\title{
Research of Laser Cladding on Mold Copper Plate Surface
}

\author{
$\mathrm{Fu}$ Wei \\ Shanghai Baosteel Industry technology Service Co., Ltd \\ Shanghai, China \\ e-mail: fuwei174171@baosteel.com \\ Deng Qilin \\ School of Mechanical and Power Engineering \\ Shanghai Jiao Tong University \\ Shanghai, China \\ e-mail: dengqilin@sjtu.edu.cn
}

\begin{abstract}
Adopting laser cladding technology, 3 kinds of alloy powder ( $\mathrm{Ni}, \mathrm{Fe}, \mathrm{Co})$ is successfully cladded on the surface of mold copper plate. Metallurgical bonding between cladding layer and $\mathrm{Cu}$ substrate is generated. Cladding layer has fine grained structure without micro-crack and bubble. The average hardness of Ni-based cladding layer is 672.3HV0.5, which is 6.5 times of the average hardness of $\mathrm{Cu}$ substrate. The major constituent phases of $\mathrm{Ni}$-based cladding layer are $\gamma-\mathrm{Ni}$ austenite phase, $\mathrm{CrB}$ compound phase, $\mathrm{M7C3}$ and M23C6 carbonization phase, and Ni3Si phase. The average hardness Fe-based cladding layer is 502.5 HV0.5, which is about 5.5 times of the average hardness of $\mathrm{Cu}$ substrate. Co-based cladding layer has higher hardness than Ni-based and Fe-based. The average hardness Co-based cladding layer is $810 \mathrm{HV0.5}$, which is about 7.2 times of the average hardness of $\mathrm{Cu}$ substrate. The main composition of cladding layer is $\mathrm{Co}, \mathrm{Cr}$ and a bit of $\mathrm{Ni}, \mathrm{Fe}, \mathrm{W}$. The major constituent phases of cladding layer are $\gamma$-Co austenite phase, (Fe, Ni) solid solution phase, $\mathrm{CrCo}$ compound phase, $\mathrm{CoCx}$ and $\mathrm{Cr} 7 \mathrm{C} 3$ carbonization phase, and $\mathrm{Mn3Co} 7$ phase.
\end{abstract}

Keywords-laser cladding; Mold Copper Plate, Ni-based alloy; Ni-based alloy;Co-based alloy

\section{INTRODUCTION}

Mold, regarded as "heart" of continuous caster, is the most critical component in continuous casting manufacture. It shapes liquid steel into expected model after solidification. As significant thermal conductor in continuous casting manufacture to transform liquid steel into solidified slab shell, mold copper plate leads liquid steel to fast and homogeneous cooling, in order to generate primary slab shell with uniform thickness and good surface. In continuous caster manufacture procedure, one side of copper plate, which is in contact with liquid steel (slab shell), conducts a lot of heat into cooling water. At present, $\mathrm{CrZrCu}$ is widely used in mold copper plate. Although $\mathrm{CrZrCu}$ has good thermal conductivity, it has low hardness. What's more, its hardness becomes lower with temperature rising. Mold copper plate works in severe surroundings. For one thing, it needs to sustain very high temperature due to in contact with liquid steel. For another, its surface needs to sustain fierce abrasion from slag materials on the surface of liquid steel and oxide coating on the surface of

\author{
Cao Peng \\ CSIG, DCG \\ Intel Asia-Pacific Research and Development Ltd \\ Shanghai, China \\ e-mail: caopeng666@gmail.com
}

\author{
Chen Dianbing \\ School of Mechanical and Power Engineering \\ Shanghai Jiao Tong University \\ Shanghai, China \\ e-mail: chendianbing111@163.com
}

steel slab. These severe surroundings lead to various defects such as scar, abrasion, corrosion and hot crack, which severely restrict the service life of mold copper plate.

In order to lengthen service life of mold copper plate, it's essential to implement strengthening processing on the surface of copper plate. Nowadays, electroplating and thermal spraying are two methods of strengthening processing applied both domestically and overseas. Electroplating was used long ago and is still widely applied now in steel industry. Its principle is plating a layer of wearable metal on the surface of copper plate to lengthen the service life. Although this method has advantages like technology is mature and workpiece deformation is little, it has more disadvantages, such as restricted plating materials, inefficiency, weak strength of mechanical bond between plating layer and copper plate. Furthermore, it has high destructive effect on environment. Thermal spraying is the other surface strengthening processing method used in recent years. Its advantages cover various materials, little deformation of workpiece, high efficiency. But the spraying thickness is limited, and the spraying layer is also mechanically jointed with copper plate. So the conjunction strength is low and the spraying layer easily sheds in daily use.

Laser cladding, getting extensive attention in recent years, is another surface strengthening and repairing technology. It has a lot of advantages: various cladding materials, high efficiency, energy concentration, low overall thermal input, little deformation of workpiece, high metallurgical bonding strength between cladding layer and substrate.

In spite of the obvious advantages of laser cladding in workpiece surface strengthening and repairing, a lot of difficult technical problems exist due to its late development, especially the intense reflection of copper against laser. It has not been industrialized in copper plate surface strengthening and repairing. It is still under lab research and in the early stage of engineering.

In this paper, based on widely used surface strengthening materials like $\mathrm{Fe}, \mathrm{Co}$ and $\mathrm{Ni}$ alloy powder in mold copper plate electroplating and thermal spraying technologies, research of laser cladding on the surface of 
copper plate is carried out, which lay the foundation for the engineering application of laser cladding technology in mold copper plate surface strengthening.

\section{EXPERIMENTAL METHOD}

First, this paper selects Ni-based self-fluxing alloy powder. The composition is shown in TABLE I. As Febased self-fluxing alloy powder has good wear resistance and low price, it can reduce processing cost to a large extent if it can form nice cladding layer in the surface of mold copper plate. So this paper selects it as cladding material for experiment and analysis. The composition is shown in TABLE II. Meanwhile, because Co-based selffluxing alloy powder has good performance such as hightemperature behavior, corrosion resistance and wear resistance, it is selected as cladding material. Stellite 6 powder is mainly used. The composition is shown in TABLE III

We study cladding layer performance differentiation of various alloy powder materials, master the performance parameters of these cladding materials, integrally grasp technology characteristics of laser cladding, seek appropriate cladding materials for mold copper plate, and provide theoretical and practical support for optimizing technological parameters.

TABLE I. COMPOSITION OF NI-BASED ALLOY POWDER

\begin{tabular}{|l|c|c|c|c|c|c|}
\hline \multirow{2}{*}{ Material } & \multicolumn{7}{|c|}{ Composition } \\
\cline { 2 - 7 } & $\boldsymbol{N i}$ & $\boldsymbol{C}$ & $\boldsymbol{B}$ & $\boldsymbol{S i}$ & $\boldsymbol{C r}$ & $\boldsymbol{F e}$ \\
\hline $\begin{array}{l}\text { Ni-based } \\
\text { alloy }\end{array}$ & Bal. & $0.70-$ & $3.00-$ & $3.50-$ & $15.00-$ & $\leq 3.00$ \\
\hline
\end{tabular}

TABLE II. COMPOSITION OF FE-BASED ALLOY POWDER

\begin{tabular}{|l|c|c|c|c|c|}
\hline \multirow{2}{*}{ Material } & \multicolumn{5}{|c|}{ Composition } \\
\cline { 2 - 6 } & $\boldsymbol{F e}$ & $\boldsymbol{C}$ & $\boldsymbol{S i}$ & $\boldsymbol{M n}$ & $\boldsymbol{S}$ \\
\hline \multirow{3}{*}{$\begin{array}{l}\text { Fe-based } \\
\text { alloy }\end{array}$} & Bal. & $\leq 0.03$ & $\leq 1.0$ & $\leq 2.0$ & $\leq 0.03$ \\
\cline { 2 - 6 } & $\boldsymbol{P}$ & $\boldsymbol{C r}$ & $\boldsymbol{N i}$ & $\boldsymbol{M o}$ & \\
\cline { 2 - 6 } & $\leq 0.035$ & $\begin{array}{l}16.00 \sim \\
18.00\end{array}$ & $\begin{array}{c}12.00 \sim \\
16.00\end{array}$ & $\begin{array}{c}2.00 \sim \\
3.00\end{array}$ & \\
\hline
\end{tabular}

TABLE III. COMPOSITION OF CO-BASED ALLOY POWDER

\begin{tabular}{|l|c|c|c|c|c|}
\hline \multirow{3}{*}{ Material } & \multicolumn{5}{|c|}{ Composition } \\
\cline { 2 - 6 } & $\boldsymbol{C o}$ & $\boldsymbol{N i}$ & $\boldsymbol{F e}$ & $\boldsymbol{C}$ & $\boldsymbol{C r}$ \\
\hline \multirow{3}{*}{$\begin{array}{l}\text { Co-based } \\
\text { alloy }\end{array}$} & Bal. & $\leq 3.00$ & $\leq 3.00$ & 1.20 & 28.00 \\
\cline { 2 - 6 } & $\boldsymbol{M n}$ & $\boldsymbol{S i}$ & $\boldsymbol{W}$ & & \\
\cline { 2 - 6 } & 1.00 & 1.10 & 4.50 & & \\
\hline
\end{tabular}

In the experiment, the laser is $3 \mathrm{KW} \mathrm{CO} 2$ transverseflow, metal substrate is $\mathrm{Cr}-\mathrm{Zr}-\mathrm{Cu}$, and sample dimension is $50 \mathrm{~mm} \times 70 \mathrm{~mm} \times 20 \mathrm{~mm}$. The sample is polished to wipe out oxide, washed by propyl alcohol, and sand-blasted. The technological parameters of laser cladding are: laser power $\mathrm{P}=2200 \mathrm{w}$, spot diameter $\mathrm{D}=5 \mathrm{~mm}$, traverse speed $\mathrm{v}=5 \mathrm{~mm} / \mathrm{s}$, overlap ratio $\lambda=50 \%$, powder feeding speed $\mathrm{l}=5 \mathrm{~g} / \mathrm{min}$. The preparation of metallographic sample includes sample cutting, insetting, grinding, and polishing, etc. Moderately corrode the polished metallographic sample using $\mathrm{FeCl} 3$ hydrochloric solution. Observe sample morphology under the metallographic microscope and capture pictures by metallographic interactive system. Measure hardness of cladding layer and substrate using Vickers hardness tester loading force is $500 \mathrm{~g}$, retention time is $15 \mathrm{~s}$.

\section{EXPERIMENTAL RESULT AND ANALYSIS}

A. Ni-based cladding layer microscopic structure analysis
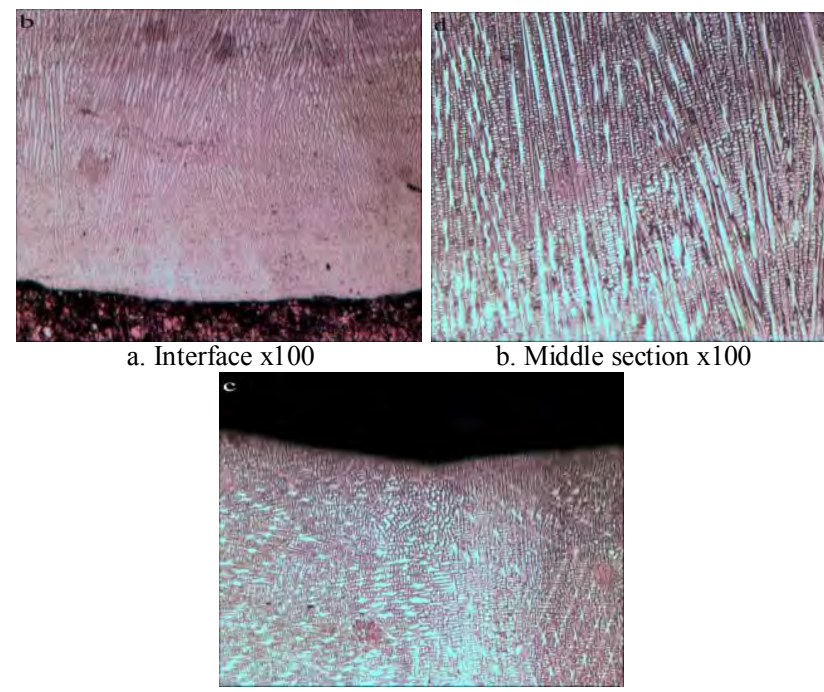

c. Roof section $\mathrm{x} 100$

Figure 1. Ni-based alloy cladding layer metallographic structure

Fig .1 shows metallographic structure of interface of cladding layer and substrate, middle section and roof section of cladding layer for Ni-based alloy. The interface is clearly visible. The cladding layer structure is compact and uniform without microcosmic defect like crack, bubble and mixture, etc. It's directional solidified cylindrical crystal. The conjunction between cladding layer and substrate is nice.

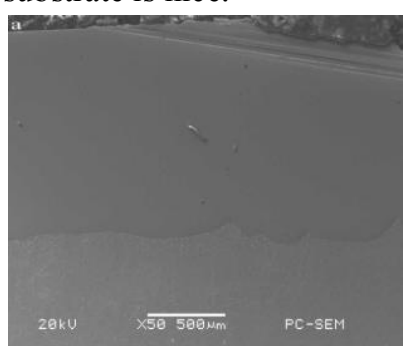

a. Overall structure
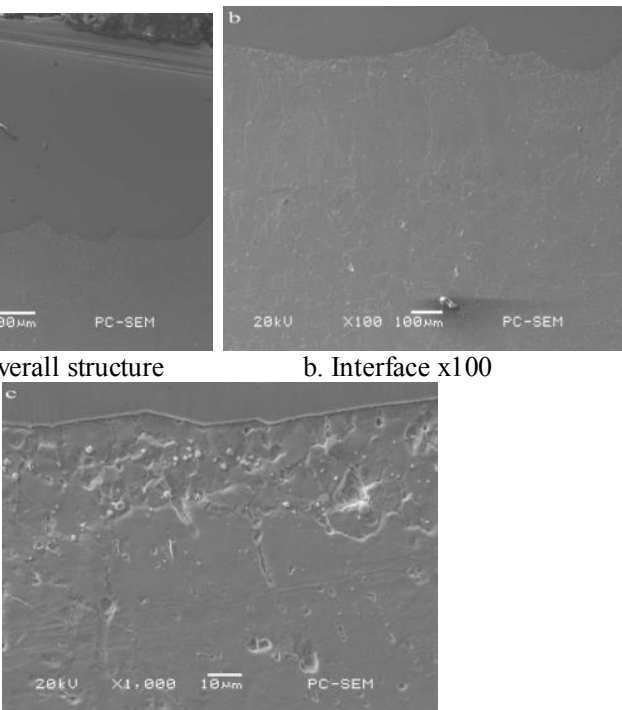

c. Interface $\mathrm{x} 1000$

Figure 2. Ni-based alloy cladding layer SEM structure 


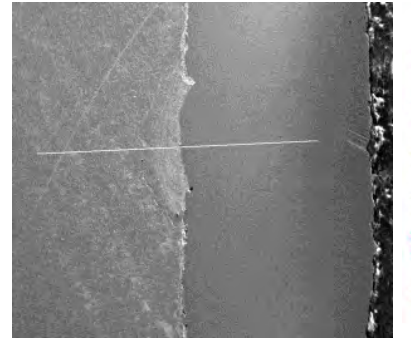

a. Scanning location and track

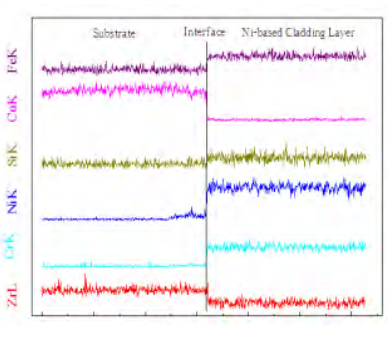

b. Element distribution
Figure 3. Ni-based cladding layer and substrate line scanning

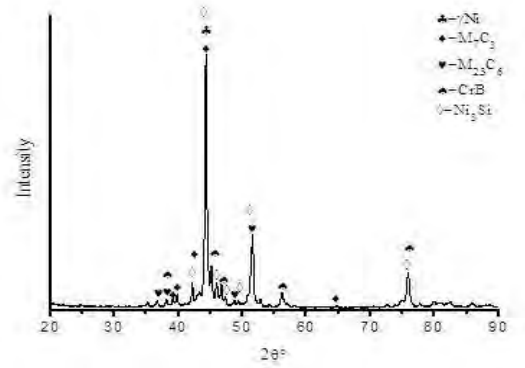

Figure 4. Ni-based cladding layer XRD

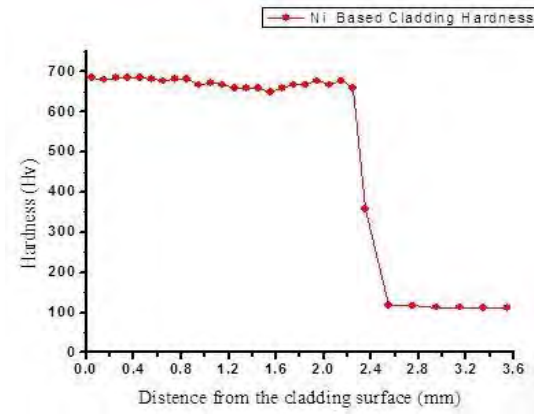

Figure 5. Ni-based cladding layer microscopic hardness

Fig .2 shows Ni-based cladding layer SEM microscopic structure. Similarly, from Fig .2 we can see there are no defects like crack, bubble, etc. and conjunction between cladding layer and substrate is good. There is an approximate $20 \mu \mathrm{m}$ conjunction belt, which means metallurgical bonding between cladding layer and substrate is generated.

Fig .3 shows SEM linear scanning of Ni-based cladding layer and $\mathrm{Cu}$ substrate. The scanning track is interpreted by white line in Fig .3a, from substrate to cladding layer. From Fig .3b we can see, cladding layer is mainly constituted by $\mathrm{Ni}, \mathrm{Cr}, \mathrm{Fe}$ and $\mathrm{Si}$. Elements like $\mathrm{Cu}$, $\mathrm{Ni}$ and $\mathrm{Fe}$ appear in the interface of cladding layer, which means metallurgical bonding belt between substrate and cladding layer is generated with good conjunction strength. There is a little of $\mathrm{Ni}$ in the substrate near interface to cladding layer, which means cladding layer material dilutes substrate to a certain degree. However, there are a lot of $\mathrm{Cu}$ in cladding layer, which means substrate has little dilution on cladding layer.

Fig .4 shows X-ray diffraction pattern for Ni-based self-fluxing alloy coating of laser cladding. Because some diffraction peaks corresponding to some phases in cladding layer are very close even overlapping, it's very difficult to exactly identify all the constituent phases in cladding layer.
According to analysis, the major constituent phases of $\mathrm{Ni}$ based cladding layer are $\gamma-\mathrm{Ni}$ austenite phase, $\mathrm{CrB}$ compound phase, M7C3 and M23C6 carbonization phase, and Ni3Si phase. M7C3 and M23C6 carbonization phase is hard phase, which is beneficial to improve the hardness of cladding layer.

Fig .5 shows cross-section hardness distribution diagram of Ni-based cladding layer and $\mathrm{Cu}$ substrate. The uppermost hardness is $686.5 \mathrm{HV} 0.5$. The lowermost hardness is $650.6 \mathrm{HV} 0.5$. The average hardness is $672.3 \mathrm{HV} 0.5$, which is 6.5 times of the average hardness of $\mathrm{Cu}$ substrate. The thickness of cladding layer is $2.3-2.4 \mathrm{~mm}$. The hardness of substrate interface is 357 HV0.5, which is about 3.6 times of substrate hardness. The result demonstrates that cladding layer and substrate forms good metallurgical bonding. This greatly enhances binding force between cladding layer and substrate, and is very beneficial to lengthening the service life of mold copper plate that lies in large temperature gradient.

\section{B. 3.2. Fe-based cladding layer microscopic structure analysis}
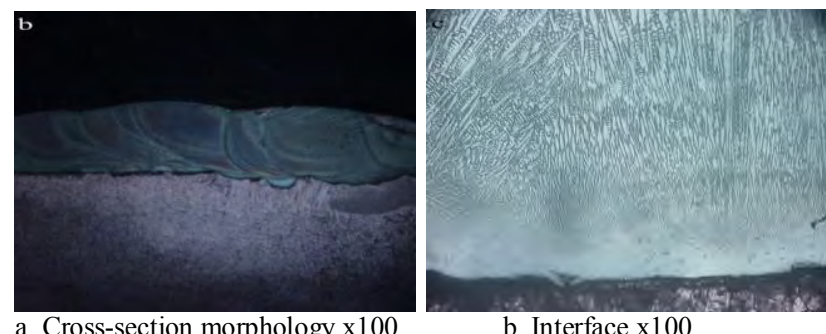

b. Interface $\mathrm{x} 100$

Figure 6. Fe-based alloy cladding layer metallographic structure

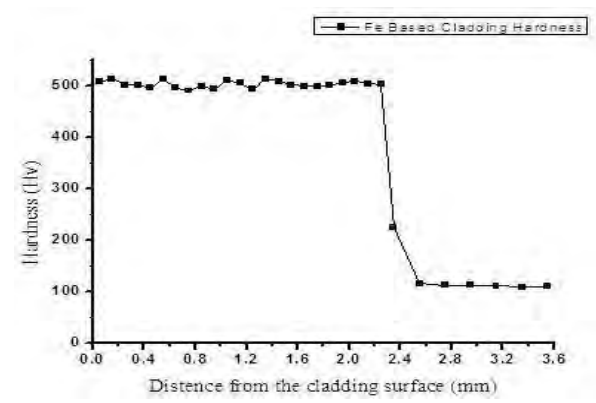

Figure 7. Fe-based cladding layer microscopic hardness

Fig .6a shows cladding layer overall structure of $\mathrm{Fe}$ based alloy on top of $\mathrm{Cu}$ substrate. There are no defects like micro-crack and bubble in cladding layer. Heat affected zone of substrate is narrow. Because the amplification factor of the figure is low, the conjunction condition of cladding layer and substrate interface can't be observed clearly. But we can see fish scale overlap in cladding layer clearly.

Fig .6b shows interface of Fe-based cladding layer and substrate, and middle section of cladding layer. The interface is smooth. Cladding layer and substrate have nice conjunction. The cladding layer structure is compact. The bottom is planar crystal. The middle is dendrite, and presents characteristics of typical fast solidification structure; that is - the growth direction of dendrite crystal is the same as the direction of maximum temperature gradient. The cladding layer structure shows regular change from the bottom to the surface of weld pool, i.e. 
"planar crystal-dendrite crystal-disordered crystal" successively.

Fig .7 shows cross-section hardness distribution diagram of Fe-based cladding layer and $\mathrm{Cu}$ substrate. The hardness fluctuation of overall cladding layer is little. There is no dramatically increasing or decreasing of hardness. That means the cladding layer structure is compact and uniform. The uppermost hardness is 513.3 HV0.5. The lowermost hardness is 489.6 HV0.5. The average hardness is $502.5 \mathrm{HV} 0.5$, which is 5.5 times of the average hardness of $\mathrm{Cu}$ substrate.

\section{Co-based cladding layer microscopic structure analysis}

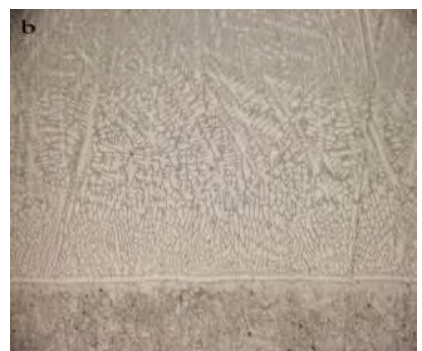

a. Interface $\mathrm{x} 100$

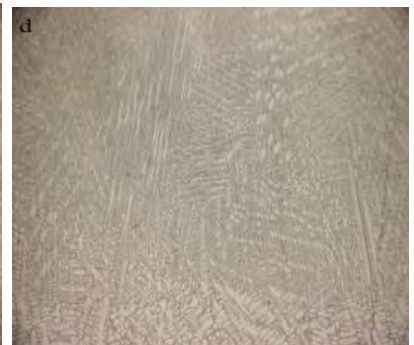

b. middle section $\mathrm{x} 100$

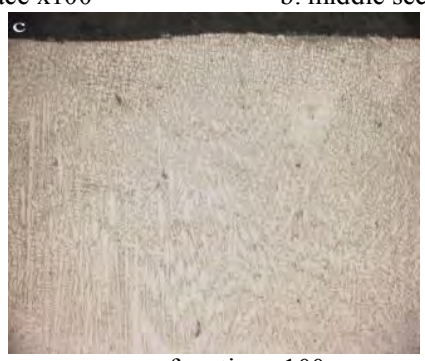

c. roof section $\times 100$

Figure 8. Co-based alloy cladding layer metallographic structure

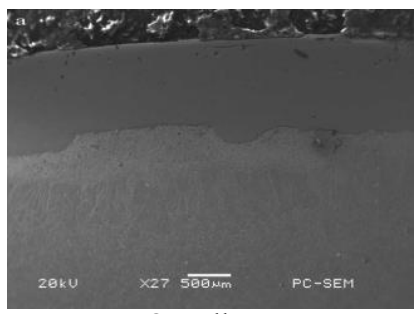

a. Overall structure

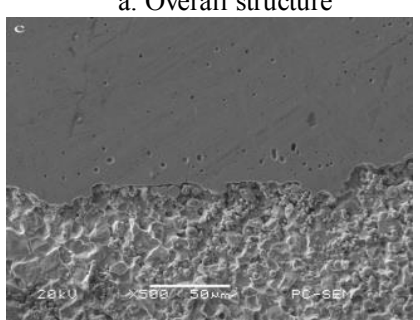

c. Interface $\mathrm{x} 500$

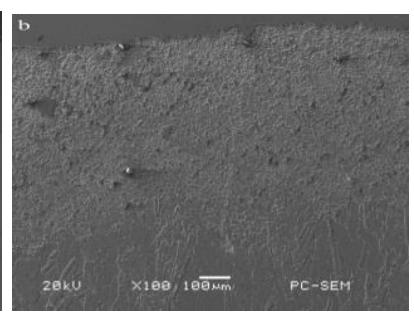

b. Interface $\mathrm{x} 100$

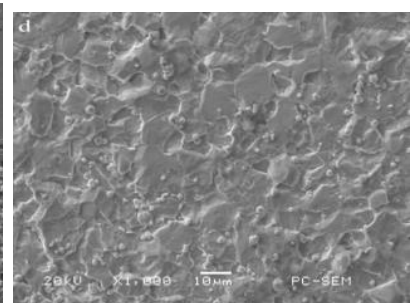

d. Metamorphic layer

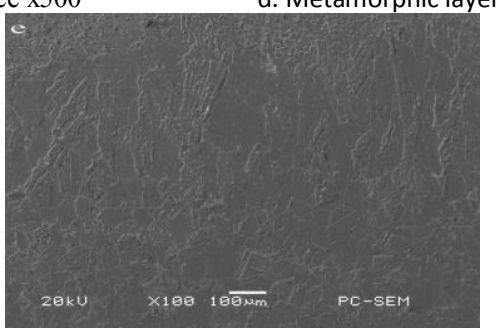

e. Substrate

Figure 9. Co-based alloy cladding layer SEM structure

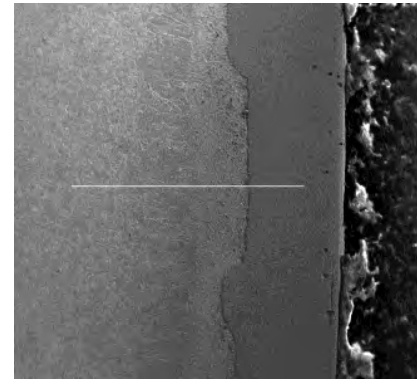

a. Scanning location and track

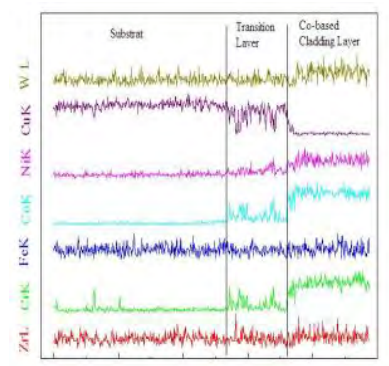

b. Element distribution
Figure 10. Co-based cladding layer and substrate linear scanning

Fig .8 shows metallographic structure of interface of cladding layer and substrate, roof section and middle section of cladding layer for Ni-based alloy. From Fig .8a we can see there is an approximate $2 \mu \mathrm{m}$ bright white narrow band between Co-based cladding layer and $\mathrm{Cu}$ substrate, which means nice metallurgical bonding is generated and the cladding layer structure is compact and uniform without micro-defect like crack. From the conjunction interface to the roof of cladding layer, the solidification structure presents the same changing trend as Ni-based cladding layer structure.

Fig .9 shows cross-section SEM structure of Co-based cladding layer. The overall structure is nice, without obvious defects like crack, bubble, mixture, etc. (Fig .9a). The interface to substrate is distinct and the conjunction quality is high. There is a "transition zone" with about $500 \mu \mathrm{m}$ thickness between cladding layer and substrate heat affected zone (Fig .9b).

Fig .10 is linear scanning track and corresponding element distribution of Co-based cladding layer and substrate. The linear scanning starts from substrate, through the whole transition layer, ends at the middle of cladding layer (Fig .10a). The main composition of cladding layer is $\mathrm{Co}, \mathrm{Cr}$ and a bit of $\mathrm{Ni}, \mathrm{Fe}, \mathrm{W}$. The main composition of transition layer between cladding layer and substrate is $\mathrm{Cu}, \mathrm{Co}, \mathrm{Cr}$ and a bit of $\mathrm{Fe}, \mathrm{Ni}, \mathrm{Zr}$, which means the transition layer is formed by melt and cooling of substrate and cladding layer. The cladding layer interface contains a bit of $\mathrm{Cu}$ and $\mathrm{Zr}$, which means cladding layer has certain dilution. So how to further reduce the dilution of Co-based cladding layer is one of the major research directions in the future research.

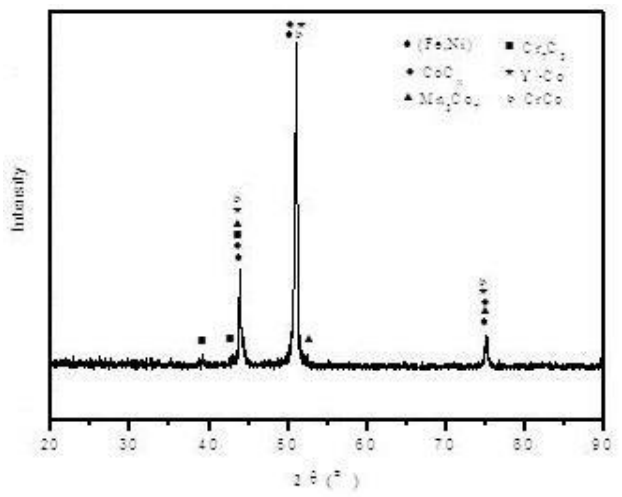

Figure 11. Co-based cladding layer XRD 


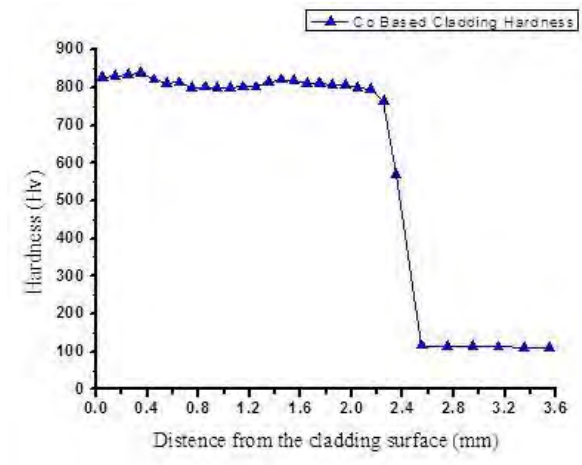

Figure 12. Co-based cladding layer microscopic hardness

Fig .11 shows X-ray diffraction pattern for cross section of Co-based cladding layer. According to the analysis, the major constituent phases of cladding layer are $\gamma$-Co austenite phase, $(\mathrm{Fe}, \mathrm{Ni}$ ) solid solution phase, $\mathrm{CrCo}$ compound phase, $\mathrm{CoCx}$ and $\mathrm{Cr} 7 \mathrm{C} 3$ carbonization phase, and $\mathrm{Mn} 3 \mathrm{Co} 7$ phase. $\gamma$-Co is typical toughness phase. Its content is high, so cladding layer has good toughness and doesn't easily crack during cladding process. $\mathrm{CoCx}$ and Cr7C3 carbonization phase is hard phase, which is beneficial to improve the micro-hardness and wear resistance of cladding layer.

Fig .12 shows cross-section hardness distribution diagram of Co-based cladding layer and $\mathrm{Cu}$ substrate. Among the 3 kind of self-fluxing alloy powder, Co-based alloy powder generated cladding layer has uppermost hardness. The uppermost hardness is 838.6 HV0.5. The lowermost hardness is $765.9 \mathrm{HV} 0.5$. The average hardness is $810 \mathrm{HV} 0.5$, which is about 7.2 times of the average hardness of $\mathrm{Cu}$ substrate. The reasons for high microhardness are: laser's rapid thermal and cooling make coating structure thin; solid solution strengthening of multiple alloy elements; dispersion strengthening of fine isolation phase. The metallographic structures of the 3 kind of cladding layer are similar but hardness differs a lot, the major reason is that material attribute is one of significant influence factors on cladding layer hardness. Co-based alloy powder contains much $\mathrm{C}$ and its cladding layer has $\mathrm{CoCx}$ and $\mathrm{Cr} 7 \mathrm{C} 3$ carbonization phase which is hard phase, so Co-based cladding layer hardness is larger than Nibased. The hardness of interface of Co-based cladding layer and substrate is $568 \mathrm{HV} 0.5$, which is about 5.7 times of $\mathrm{Cu}$ substrate. Because cladding layer hardness is much larger that substrate hardness, there is hardness mutation. Nevertheless, hardness transition zone leads the hardness mutation to smaller, which makes the hardness change a slow gradient change.

\section{CONCLUSION}

1. Adopting laser cladding technology, 3 kinds of alloy powder $(\mathrm{Ni}, \mathrm{Fe}, \mathrm{Co})$ is successfully cladded on the surface of mold copper plate. Metallurgical bonding between cladding layer and $\mathrm{Cu}$ substrate is generated. Cladding layer has fine grained structure without micro-crack and bubble.

2. The uppermost hardness of Ni-based cladding layer is $686.5 \mathrm{HV} 0.5$. The lowermost hardness is $650.6 \mathrm{HV} 0.5$. The average hardness is $672.3 \mathrm{HV} 0.5$, which is 6.5 times of the average hardness of $\mathrm{Cu}$ substrate. The major constituent phases of Ni-based cladding layer are $\gamma-\mathrm{Ni}$ austenite phase, CrB compound phase, M7C3 and M23C6 carbonization phase, and Ni3Si phase.

3. The uppermost hardness of Fe-based cladding layer is $513.3 \mathrm{HV} 0.5$. The lowermost hardness is $489.6 \mathrm{HV} 0.5$. The average hardness is $502.5 \mathrm{HV} 0.5$, which is about 5.5 times of the average hardness of $\mathrm{Cu}$ substrate.

4. Co-based cladding layer has higher hardness than Ni-based and Fe-based. The uppermost hardness is 838.6 HV0.5. The lowermost hardness is 765.9 HV0.5. The average hardness is $810 \mathrm{HV} 0.5$, which is about 7.2 times of the average hardness of $\mathrm{Cu}$ substrate. The main composition of cladding layer is $\mathrm{Co}, \mathrm{Cr}$ and a bit of $\mathrm{Ni}, \mathrm{Fe}$, $\mathrm{W}$. The major constituent phases of cladding layer are $\gamma$ Co austenite phase, ( $\mathrm{Fe}, \mathrm{Ni})$ solid solution phase, $\mathrm{CrCo}$ compound phase, $\mathrm{CoCx}$ and $\mathrm{Cr} 7 \mathrm{C} 3$ carbonization phase, and $\mathrm{Mn} 3 \mathrm{Co} 7$ phase.

\section{ACKNOWLEDGMENTS}

This research was financially supported by the National Natural Science Foundation of China (No. 51275303).

\section{REFERENCES}

[1] ZHANG Weiping, MA Haibo, Current Status of Studies on Laser Cladding of Copper Alloys, Materials for Mechanical Engineering, Sep. 2009, Vol.33 No.9.

[2] REN Hu-ping, YANG Gui-rong, et al, Improvement of Surface Modification Technology of Copper Alloy, Foundry, Mar. 2005, Vol.54 No.3.

[3] LIU Fang, LIU Chang-sheng, et al, Progress in Surface Treatment of Copper Crystallizer, Surface Technology, Jun. 2006, Vol.35 No.3, pp. 1-3

[4] Ge Zhijun, Deng Qilin, et al, Status and Development of Laser Cladding on Non-ferrous Metals, Electromachining \& Mould, 6(2006), pp. 1-4.

[5] LIU Fang, LIU Chang-sheng, et al, Laser cladding of Ni-based alloy on copper substrate, Journal of University of Science and Technology Beijing, Aug. 2006, Vol. 13. No.4, pp. 329-332.

[6] DEHM G., MEDRES B., et al, Microstructure and tribological properties of Ni-based claddings on $\mathrm{Cu}$ substrates, Wear 225-229 (1999) 18-26.

[7] Sandip Bysakh, Kamanio ChattoPadhyay, et al, Microstructure evolution in laser alloyed layer of $\mathrm{Cu}-\mathrm{Fe}-\mathrm{Al}-\mathrm{Si}$ on $\mathrm{Cu}$ substrate, Materials Science and Engineering. A, 375-377 (2004) 661-665.

[8] M. Khalid Imran, S.H. Masood, et al, Direct metal deposition (DMD) of H13 tool steel on copper alloy substrate: Evaluation of mechanical properties, Materials Science and Engineering A 528 (2011) 3342-3349

[9] Yang Jiaoxi, Zuo Tiechuan, et al, Microstructure of Laser Cladding Ni-Base Alloy on Manganese Bronze, Chinese Journal of Lasers, Nov. 2008, Vol.35 No. 11, pp. 1766-1769.

[10] Yong-zhong Zhang, Yi Tu, et al, Characterization on laser clad nickel based alloy coating on pure copper, Surface \& Coatings Technology 202 (2008) 5924-5928.

[11] Hua Yana, Aihua Wanga, *, Kaidong Xua, Wenyan Wangb, Zaowen Huanga, Microstructure and interfacial evaluation of $\mathrm{Co}$ based alloy coating on copper by pulsed Nd:YAG multilayer laser cladding, Journal of Alloys and Compounds 505 (2010) 645-653 